\title{
Contenido y Alcance de la Zona Marítima Peruana de Soberanía y Jurisdicción Nacional
}

\section{Jaime Alva Kattan}

$\mathrm{U}$ NO DE LOS TEMAS más conflictivos a nivel de interpretación jurídica es, sin lugar a ninguna duda, el de la naturaleza jurídica de la reivindicación peruana sobre el espacio marítimo de 200 millas náuticas, donde el Estado ejerce soberanía y jurisdicción.

Dicha apreciación no ha escapado a la atención de la doctrina extranjera y asf, en opinión de Pfirter de Armas", "La posición peruana en relación con el derecho del mar en general y del mar territorial en particular, ha sido objeto de interpretaciones conflictivas durante un cuarto de siglo. En gran parte se ha debido a la naturaleza contradictoria de la legislación y de los pronunciamientos peruanos...".

El tema se encuentra estrechamente relacionado con la Convención de las Naciones Unidas sobre el Derecho del $\mathrm{Mar}^{2}$ ya que, según a la conclusión que se llegue sobre la caracterización jurídica de dicha reivindicación, será menester preguntarse si cabe o no adecuar la Constitución Peruana y la legislación secundaria al orden jurídico del mar.

Quienes sostienen que el Estado Peruano ejerce una soberanía modal, limitada o funcional para los efectos de resguardar y explotar los recursos naturales vivos $y$ no vivos del mar adyacente, afirman ${ }^{3}$ que no es nece-

1 Pfirter do Armas, $F_{4,}$ Perú: La matcha hacta el Oeste, en El derecho del mar en la evolucib́n: la contribación de los países latinosmeticanos, Zacklin ed., México 1975, p. 296.

2 Doc, A/CONF, 62/122 del 7 de octubre de 1982.

3 Arias Schreiber, A., La Comención de Dereche del Mat y las 200 millas, en Revista del Foro, No, 1, Limk, 1982, p. 155. 
sario reformar la Constitución; mientras que los que son de parecer contrario sobre el contenido y los alcances de la legislación nacional atribuyéndole una connotación territorialista, opinan ${ }^{4}$ que ésta deberá armonizarse con las disposiciones de la Convención.

El asunto, ha sido tratado recientemente por la Comisión Especial del Colegio de Abogados de Lima a través de un dictamen dado a conocer a la opinión pública por el diario "El Comercio" de fecha 29-12-82 5 . El referido dictamen, expresa que la Doctrina Peruana sobre las 200 millas "no responde a la tesis del mar territorial ya que no reúne los elementos tipificantes", siendo uno de ellos, el concepto de paso inocente que es, por su naturaleza, una institución típica del mar territorial.

Seguidamente, la Comisión Especial, como corolario de lo arriba expresado, sostiene que "no existe incompatibilidad entre la Constitución del Perú y el texto de la Convención sobre el Derecho del Mar, ya que la llamada zona económica exclusiva de 200 millas contempla el derecho de soberanfa modal y tiene normas relativas a su ejercicio y al dominio sobre los recursos naturales vivos y no vivos que se encuentran en ella".

Estas consideraciones, por cierto muy respetables, carecen en nuestra opinión de sustento jurídico y nos inducen a escribir una vez más sobre este tema de fundamental importancia para el país.

En nuestra opinión, para una visión objetiva del asunto es menester hacer un análisis de conjunto de la legislación y analizarla a la luz del derecho internacional marítimo, por cuanto la definición del concepto de mar territorial corresponde a este ordenamiento jurídico y no debe estar sujeto a la interpretación unilateral de los Estados, ni tanto menos de la doctrina.

Ahora bien, para dar una idea general de qué se entiende por mar territorial conviene decir que es la franja de mar adyacente a las costas de un Estado ribereño, donde éste ejerce una soberanía territorial en los tres planos geográficos que lo integran, a saber: la superficic y el

4 Alva Kattín, J, El dominio marítimo en la Constituciōn y la Convencióa de la ONU, en Oigz, No. 98, 25 de octubre de 1982, p. 13.

5 Para el tex to completo del dictamen véase: Colegio de A bogados de Lima, Las doscientas millas y la Convención sobre Derecho del Mar, Lima, 1983. 
volumen de sus aguas, el espacio áreo suprayacente y el lecho y subsuelo subyacentes ${ }^{6}$.

Esta definición, corresponde exactamente a lo normado en el artículo 2 del Tratado de Convención sobre el Derecho del Mar cuyo título se refiere al régimen jurídico del mar territorial, del espacio aéreo situado sobre dicho mar y de su lecho y subsuelo, donde se proyecta la soberanía del Estado costero?

Sin temor a equivocarnos, creemos que los elementos relativos a este instituto jurídico están presentes en la legislación peruana.

Ello se advierte, en lo que respecta al espacio marítimo, de la simple lectura del Decreto Supremo No. 781 de 1 de agosto de 1947 y de los párrafos pertinentes de la Declaración de Santiago de 1952 suscrita y ratificada posteriormente por Chile, Perú y Ecuador, mediante la cual los paises signatarios crearon una zona marítima de 200 millas.

A través de estos instrumentos legales, el Perú extiende su soberanía y jurisdicción a las áreas submarinas así como sobre el mar adyacente hasta la distancia de 200 millas, con el deliberado propósito de reservar, proteger, conservar y utilizar los recursos y riquezas naturales allf existentes.

Si bien los derechos que se persiguen son exclusivamente de carácter económico, ello no significa que el Perú condicione o limite el ejercicio de su soberanía y jurisdicción al cumplimiento de uno o varios de los fines especificos precitados y que haya, por ende, renunciado jurídicamente a los demás derechos soberanos que corresponden al mar territorial.

Al contrario, la preocupación del Perú por el destino de los derechos residuales de otra indole perteneciente a este instituto jurídico, fue puesta de manifiesto por la delegación peruana en la Segunda Comisión Preparatoria de la Tercera Conferencia Internacional sobre el Derecho del Mar, de la siguiente manera: " $\mathrm{El}$ derecho internacional es una disciplina viva. Evoluciona constantemente a la luz de nuevas realidades que van

6 Armsi Basen, Calixto A, Competencias del Estado ribertĩo sobte los ámbitos geograficos comprendidos en el mar territorial, separata del Anuario del Instituto Hispano-Luso-Americano de Derecho laternacional, Madrid, 1973, p. 494.

7 Articulo 2, párrafo 1 y 2. 
surgiendo en un mundo en ebullición. De ahí que ese derecho internacional dinámico permita la evolución de sus propios postulados, como sería el caso de un mar territorial amplio con pluralidad de regímenes, dentro del cual quedaria plenamente reconocida la soberania del Estado costero para ejercer, entre otros derechos, el de regular la protección y aprovechamiento de recursos vivos como no vivos, sin por ello resultar afectadas dentro de los límites adecuados las necesidades de la navegación, sobrevuelo $\mathrm{y}$ demás comunicaciones internacional que interesa a todos los Estados. Nos parece que dicha fórmula resulta más razonable que la de proponer varias zonas de jurisdicción especial en las cuales el Estado costero ejercería derechos análogos a los reconocidos dentro del mar territorial para la conservación y administración de los recursos vivos, para el aprovechamiento de esos mismos recursos mineros ....8.

Una posición concreta de lo que se viene exponiendo, que confirma y refuerza la interpretación de que la zona es un mar territorial, la tenemos con la dación del Decreto Supremo No. 027-77.EM/SG ${ }^{*}$ que aprueba el Reglamento para el ingreso y el tránsito en aguas peruanas de naves propulsadas con energía nuclear o que contengan implementos u otros artefactos que utilicen esa energía. En efecto, este es el único espacio marítimo que autoriza al Estado ribereño, a ejercer un cierto control sobre los buques extranjeros de propulsión nuclear o que transporten sustancias de ese tipo ${ }^{10}$, ya que la Convención de las Naciones Unidas sobre el Derecho del Mar, a diferencia de lo que dispone el referido Decreto Supremo, no ha establecido dentro del ámbito de la zona

8 Exposiciones oficiales peruanas sobre el Nuevo Derecho del Mar. Ministerio de Relaciones Exteriores del Perí. Lima, 1972. pág. 93. Cabe anotar, además de lo que se ha expuesto en et texto, que lo manifestado es coincidente coe la posición adoptads por la Cancillería Peruana en la XII reunáán del Comité Consultivo Legal Astítico-Africano en Lagos, Nigeria, el 21 de enero de 1972. Alli, el observador del Peń refirí́ndose sil coneepto de zona económica exclaskra propuesto inicialmente por los países africasios, sostuvo coneretamente que el Perú al igual que otros paises "consideran qae los derechos de los Estados costeros quedarian mejor protegidos mediante el mastenimiesto del coocepto de plena sobsania en ua mar territorial o nacional, cuyos limites varlatian segín los factores geogrificos y anexcs" Ibid. p. 53.

A pesas de la distinta denoeninactón que $86 \mathrm{k}$ ha querido atribuir al espacio marítimo de 200 millas como "mat nscional", se ha dicho que este termino ", ., pressupoe pertenecer to Estado elbeiriaho as competẻncias residuals decorrentes do processo de distribulgao de coenpetẻncias entre esse Estade es demais..." Marotta Rangel, V, Delimitaçao dos espacios maritimos: Vehlo e novo tema, en Temis. Revista de Ciencia y Técnica Jurídica an. 33-36, Ueiversidse et Zaraecas, 1973-74, p. 272.

9 Diario Oficial "El Peruano", 12 de enero de 1978.

10 Laurent Lucchini ot Michel Voejckel, Passage dans les eaux territorlales et sejour dans bes ports đu navire a propulsion nucleaire, en Droit Nucleaire et Dreit Oceanique. París, Económica, 1977, pig. 39 y ss. Cfr. además, los artículos 22 y 23 relativos al mar territorial del Doc. A/Canf. 62/122, cit. p. 11 . 
econónica exclusiva, norma alguna que contemple que este tipo de naves requieran la previa autorización de las autoridades competentes para el ingreso en aguas bajo la soberanía y jurisdicción del Perú.

Resulta de sumo interés a este propósito, transcribir a continuación el último párrafo de la exposición de motivos que acompaña el citado dispositivo legal, ya que en este caso, la reivindicación de 200 millas aparece identificada claramente con el mar territorial. Se dice al respecto, que: "El proyecto de Decreto Supremo que se somete a consideración y estudio, contiene las normas y demás disposiciones que deberán cumplir las naves que circulen por aguas territoriales peruanas y su ingreso $y$ estadía en puertos nacionales".

Si aún pudieran caber dudas sobre la naturaleza jurídica de la zona de 200 millas, el artículo $\mathbf{5}$ de la Declaración de Santiago las discipa definitivamente ya que hace mención, de manera expresa, al derecho de paso inocente o inofensivo, institución típica del mar territorial, y no la libertad de navegación.

A propósito de este régimen de navegación, en doctrina no existe sin embargo consenso sobre cual es el régimen prevaleciente sobre dicho espacio marítimo. Quienes se han ocupado del tema, afirmando que la zona marítima de 200 millas no es un mar territorial, sostienen que el régimen que impera es el de las libertades de comunicación internacional,

Asi, por ejemplo, recientemente se ha dicho, que la expresión constitucional: "sin perjuicio de las libertades de comunicación internacional, de acuerdo con la ley y los convenios internacionales ratificados por la República", habría sido normada por los Constituyentes "... con mucho alcance y sentido de previsión de lo que sería el nuevo derecho del mar (artículo 58 Convención), coincidiendo así el artículo 98 de la Constitución de 1979 y el espíritu de la Convención" "11 que establece, entre otras cosas, para los Estados, sean ribereños o sin litoral, el goce de la libertad de navegación por la zona económica exclusiva.

Se trata desde luego, de una interpretación que no responde al estado actual del derecho positivo nacional, pues la expresión transcrita, en relación con la Convención del Mar, pone una cuestión de ius condendum $y$ no de ius conditum, sujeta a una condición futura e incierta como

11. Dutín Abarca, W, La soberanía y las 200 millas, Lima, 1983, p, 86. 
es la aprobación y ratificación de la citada Convención como actos jurídicos tendientes a modificar el sistema jurídico vigente.

No hay ningún convenio que se refiera a la libertad de navegación; el único instrumento internacional vigente para el Perú es el del Pacífico Sur que deja a salvo el ius transitus innoxiï.

Con relación al espacio aéreo superestante al mar adyacente que se reclama para fines de defensa y control, la Ley de Acronáutica Civil de 11 de noviembre de 1965, declaró la soberanía exclusiva del Perú sobre el espacio aéreo que cubre su territorio $y$ aguas jurisdiccionales hasta un límite de 200 millas.

La misma controversia sobre los alcances de la legislación peruana que hemos visto líneas arriba, ha sido trasladada para el caso de los artículos 97, 98 y 99 de la Constitución Política del Estado que define lo que es el Dominio Marítimo, sosteniéndose que de nínguna manera se trata de un mar territorial pues la Constitución habría excluido este concepto. Dicha conclusión sería de por sí relevante si a ello se aunaran otros elementos que llevasen a una interpretación unívoca en tal sentido. Sin embargo, los artículos constitucionales citados demuestran lo contrario.

Como ya lo hemos dicho en otra oportunidad ${ }^{12}$, la Convención sobre el Derecho del Mar, al referirse a la zona económica exclusiva menciona que los Estados ribereños ejercen alli derechos de soberanía sobre los recursos y no la soberanía tal como estí tipificada en nuestra Constitución Política, que es un concepto mucho más amplio porque comprende además de los derechos de índole cconómica que el Perú ha venido ejerciendo hasta la fecha, todas las competencias residuales que pudieran derivar del ejercicio de esa soberanía, En efecto, de conformidad con el artículo 59 de la Convención, dichas competencias residuales no pertenecen en principio, al Estado costero, El artículo citado cuyo título es "Base para la solución de conflictos relativos a la atribución de derechos y jurisdicción en la zona económica exclusiva" establece que: "En los casos en que esta Convención no atribuya derechos o jurisdicción al Estado ribereño o a otros Estados en la zona económica exclusiva, y surja un conflicto entre los intereses del Estado ribereño y los de cualquier otro Estado o Estados, el conflicto debería ser resuel to sobre una base de equidad y a la luz de todas las circunstancias pertinentes, teniendo

12. Alva Kattin, J., El dominio maritimo, cit, p, 13 , 
en cuenta la importancia respectiva que revistan los intereses de que se trata para las partes, así como para la comunidad internacional en su conjunto".

La solución de estos casos a que hace mención la fórmula transcrita, se deberán resolver por separado según las circunstancias históricas del momento y teniendo en cuenta la valutación que de ellos dé la Comunidad Internacional. En este ámbito el conflicto de intereses entre el Estado tibereño y los de cualquier otro Estado o Estados se valutarán y resolverán no solamente a la luz de los contrapuestos intereses en juego entre las partes en conflicto, sino también a la luz de su adecuación (uno de ellos) con los intereses de la Comunidad Internacional. Se trata, en suma, de subordinar los intereses nacionales a los objetivos trascendentales de la equidad y de la justicia internacional que persigue la Comunidad Internacional ${ }^{13}$.

Por lo demás, no está probado que el concepto de dominio maritimo sea distinto al concepto de mar territorial. La doctrina ${ }^{14}$, y la práctica legislativa de los Estados ven a ambos como sinónimos. Por ejemplo, la Ley de Navegación y Comercio Marítimo de México de 1963 estipula (artículo 9 fracción 1) que "el mar territorial y las aquas interiores son bienes de dominio marítimo".

Pero lo que refuerza la caracterización territorialista de la zona de 200 millas es el artículo 97 de la Constitución que establece que "el territorio de la República es inviolable. Comprende el suelo, el subsuelo, el dominio marítimo y el espacio aćreo que los cubre".

En este mismo orden de ideas, es importante recordar que El Salvador, en la Constitución promulgada el 14 de setiembre de 1950, ya había establecido una reivindicación similar a la del Perú considerada por la doctrina internacional ${ }^{15}$, como la expresión de un mar territorial. El artículo pertinente dispone en efecto que el territorio del Estado "comprende el mar adyacente basta la distancia de 200 millas y abarca el espacio aéreo, el subsuelo y el zócalo continental correspondiente".

13 Alva Kattín, J La teotía de h pluralidad de regimenes en el mar tetritorial $y$ la Tercera Conforencis de las Naciones Unidas sobre el Derecho del Mar, en Revista de Derecho Marítimo y Cometcial, No. 5 / junio, Lima, 1981, p.p. 16-17.

14 Vísquez Rocha, E, La teorh furidica sobre la plataforma contineatal, Bogoth, 1963, D. 90.

is Paolitlo Felipe, H. El mar territorial y la zona contigua, en Tendencis del Derecbo del Mar contemporíneo, Orrego Viculla $\mathrm{F}_{\text {, }}$ ed., UNITAR, Bvenos Aires, 1974, D. 31. 
Creemos que si la intención de los Constituyentes peruanos que redactaron la Carta Constitucional hubiese sido la de referirse exclusivamente a una zona marítima de recursos, ellos lo hubieran manifestado con mayor énfasis incorporando dicho espacio marítimo en el título tercero, capítulo segundo de la Constitución dedicado expresamente a los recursos naturales.

Al no haberlo hecho, demostraron no haber adherido a la noción de zona cconómica exclusiva que a la fecha de la redacción de la Carta Constitucional, ya contaba con todos sus elementos esenciales al extremo que la doctrina más autorizada ${ }^{16}$, hablaba ya de una norma consuetudinaria en rápido itinere.

Es significativo a este propósito, constatar como los trabajos de la Conferencia sirvieron de guía para la práctica de los Estados quienes, en observancia de esa norma en vía de formación, in statuo nascendi, no vacilaron en incorporarla en sus respectivos ordenamientos internos, sin esperar la culminación de los trabajos de dicha Conferencia del Mar.

Es el caso por ejemplo, de Costa Rica ${ }^{17} \mathrm{y}$ de México ${ }^{18}$ que, a nivel constitucional, afirman un mar territorial de 12 millas y una zona de jurisdicción especial de 188 millas náuticas (z.e.e.).

Este último espacio marítimo, como puede verse claramente de los preceptos de la Constitución Mexicana que se refieren al territorio, no ha sido comprendido dentro de este ámbito territorial, pues su ubicación legislativa enfatiza que éste se encuentra situado fuera del mar territorial.

La situación reseñada, plantea pues para el Perú la necesidad de armonizar su legislación con el derecho del mar, en concordancia con la jurisprudencia sentada en 1951 por la Corte Internacional de Justicia, en el juicio sobre las pesquerias anglo-noruegas. Según este fallo, la delimitación de los espacios marítimos tiene siempre un aspecto internacional

16 Conforti, B., Appunti alle lezioni di diritto intemazionale, Napoli, 1976, p. 143.

17 Romero Pérez, JE, Un aspecto ded Derecho del Mar: La plataforma continental y sas correlatos, en Revista de Ciencias Jurfidicas, No, 31, San José, Costa Rica, 1977, p. 138.

18 Sepúlveda, C., Detecho Internacional Pública, México, 1976, P.p. 569 - 570. 
y no depende exclusivamente de la voluntad unilateral de un Estado ribereño, expresada en su derecho interno.

Desde ese punto de vista, la validez y la eficacia de la delimitación marítima, con respecto a otros Estados, depende del Derecho Internacional. 